\title{
Identification and Quantitation of the Lipation product 2-Amino- 6-(3-methylpyridin-1-ium-1-yl)hexanoic acid (MP-lysine) in \\ Peanuts
}

Martin Globisch, Meike Deuber and Thomas Henle*

Institute of Food Chemistry, Technische Universität Dresden, D-01062 Dresden, Germany

Supporting information

Figure I<smiles>C=CC=NOCc1c(F)c(F)c(F)c(F)c1F</smiles>

Fig. I Derivatization reaction of acrolein by o-(2,3,4,5,6-pentafluorobenzyl)hydroxylamine (PFBHA). 


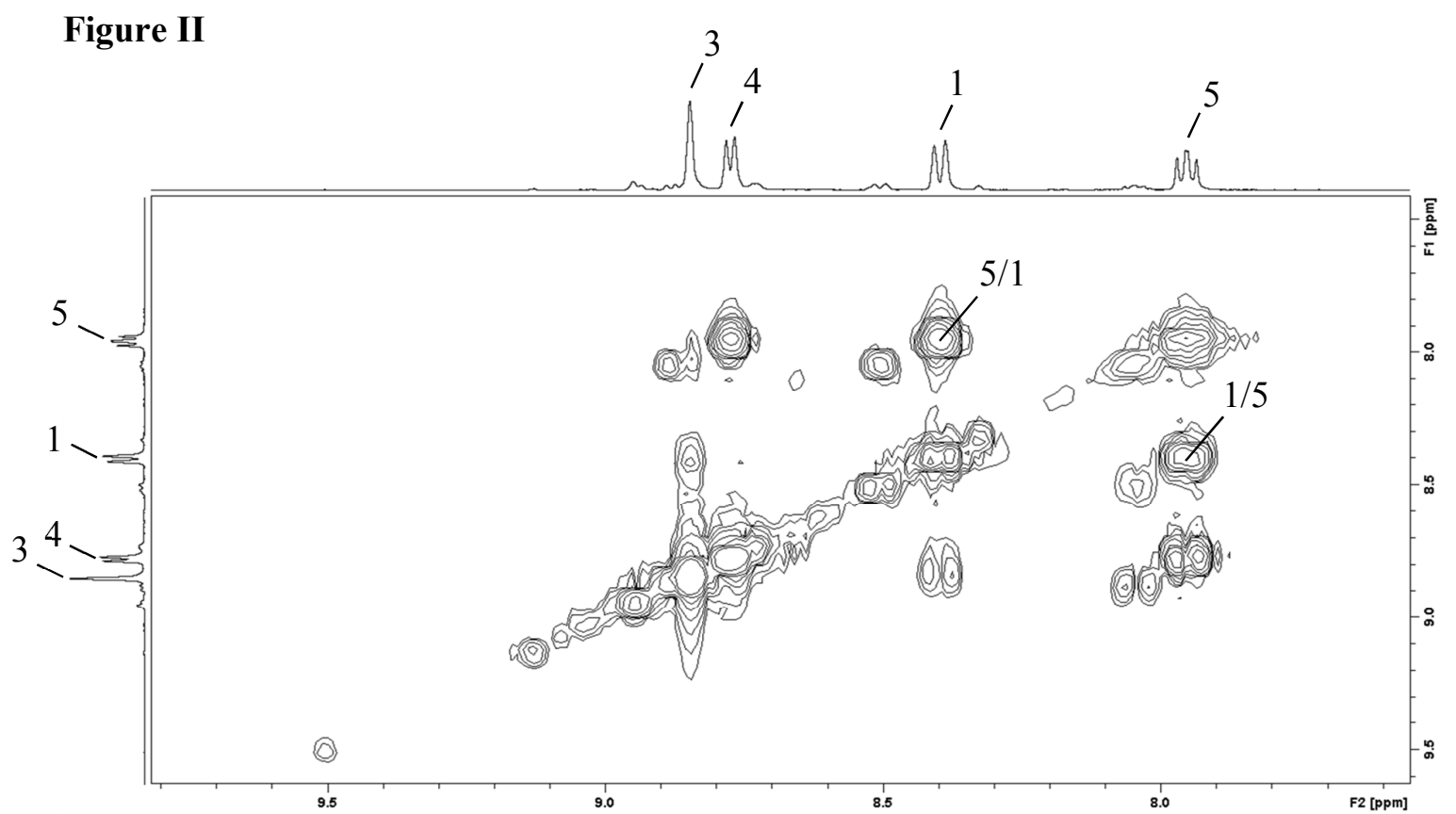

Fig. II COSY spectrum of 2-Amino-6-(3-methylpyridin-1-ium-1-yl)hexanoic acid (MPlysine) showing the correlation between $\mathrm{H}-1$ and $\mathrm{H}-5$. 